\title{
PENGARUH SISTEM OLAH TANAH DAN PEMBERIAN MULSA TERHADAP KEHILANGAN UNSUR HARA (N,P,K) DAN C-ORGANIK AKIBAT EROSI PADA PERTANAMAN KACANG HIJAU MUSIM TANAM KETIGA
}

\author{
THE EFFECT OF SOIL TILLAGE SYSTEM AND MULCH APPLICATION ON \\ THE LOSS OF NUTRIENTS (N, P, K) AND ORGANIC CARBON DUE TO \\ EROSION AT THE THIRD SEASON OF GREEN BEAN CULTIVATION
}

\author{
Rio Anugrah Putra*, Irwan Sukri Banuwa, Supriatin dan Muhajir Utomo \\ Jurusan Agroteknologi Fakultas Pertanian Universitas Lampung \\ JL. Prof. Dr. Soemantri Brojonegoro, No. 1 Bandar Lampung 35145 \\ *E-mail: anugrahluthan@gmail.com
}

\begin{abstract}
This study aimed to determine the effect of tillage system, mulch application, and interactions between them on the loss of nutrients (N, $, K, K)$ and organic carbon due to erosion on green bean cultivation. This research was conducted in March until June 2017 at the Integrated Field Laboratory of Agriculture Faculty, University of Lampung. This research used a Randomized Complete Block design (RCB) with two treatment factors, namely tillage system and mulch application, and four replications. The results showed that the conservation tillage system, mulch application and the interaction between them did not significantly affect the total $N$-content, available-P, exchangeable-K and organic carbon content in the sediment.
\end{abstract}

Keywords: erosion, mulch, nutrient, soil tillage system.

\begin{abstract}
ABSTRAK
Penelitian ini bertujuan untuk mengetahui pengaruh sistem olah tanah, penggunaan mulsa, dan interaksi antar keduanya terhadap kehilangan unsur hara $(\mathrm{N}, \mathrm{P}, \mathrm{K})$ dan C-organik akibat erosi pada lahan pertanaman kacang hijau. Penelitian ini dilakukan pada Maret sampai Juni 2017 di Laboratorium Lapang Terpadu Fakultas Pertanian Universitas Lampung. Rancangan yang digunakan adalah Rancangan Acak Kelompok Lengkap (RAKL) dengan dua faktor perlakuan yaitu sistem olah tanah dan pemberian mulsa, dan empat kali ulangan. Hasil penelitian menunjukkan bahwa perlakuan sitem olah tanah konservasi, perlakuan mulsa dan interaksi antara keduanya tidak berpengaruh nyata terhadap kandungan N-total, P-tersedia, K-dd dan C-organik dalam sedimen.
\end{abstract}

Kata kunci: erosi, mulsa, sistem olah tanah, unsur hara. 


\section{PENDAHULUAN}

Perbandingan luas lahan pertanian dengan populasi penduduk semakin menurun dengan semakin bertambahnya waktu. Penurunan tersebut disebabkan oleh pertambahan penduduk yang tidak seimbang dengan perluasan areal pertanian baru. Jumlah penduduk yang semakin meningkat ini perlu diimbangi dengan peningkatan produksi pertanian terutama pangan. Salah satu alternatif untuk meningkatkan produksi pertanian adalah ekstensifikasi atau perluasan areal pertanian. Ekstensifikasi yang paling memungkinkan yaitu perluasan areal pertanian lahan kering atau lahan pertanian yang berlereng (Wardani, 1990).

Permasalahan yang perlu diperhatikan pada lahan kering dan berlereng adalah produktivitas yang cepat menurun. Penurunan produktivitas tanah antara lain disebabkan oleh pemanfaatan lahan yang tidak sesuai dengan kemampuannya, terjadinya erosi dan kemunduran kesuburan tanah. Erosi umumnya terjadi akibat terbukanya permukaan tanah untuk usaha pertanian sehingga mudah terkena tumbukan energibutir hujan yang jatuh (Wardani, 1990).

Menurut Arsyad (2010) erosi menyebabkan hilangnya lapisan tanah yang subur dan baik untuk pertumbuhan tanaman serta berkurangnya kemampuan tanah untuk menyerap dan menahan air. Tanah yang terangkut tersebut akan diendapkan di tempat lain. Dengan demikian, kerusakan yang ditimbulkan oleh peristiwa erosi terjadi di dua tempat, yaitu pada tanah tempat erosi terjadi dan pada tempat tujuan akhir tanah yang terangkut tersebut diendapkan. Kerusakan yang dialami pada tanah tempat erosi terjadi berupa kemunduran sifat-sifat kimia dan fisik tanah seperti kehilangan unsur hara dan bahan organik serta memburuknya sifat-sifat fisik. Hal ini disebabkan oleh hilangnya lapisan atas tanah setebal $15-30 \mathrm{~cm}$ yang mempunyai sifat-sifat kimia dan fisik lebih baik dari pada lapisan tanah di bawahnya (Arsyad, 2010).

Dalam jangka pendek erosi menyebabkan penurunan produkitivitas tanah, sedangkan dalam jangka panjang erosi menyebabkan pendangkalan waduk, danau, sungai dan saluran irigasi. Selain itu, unsur-unsur hara yang terangkut oleh erosi dapat menyebabkan polusi di daerah aliran sungai, waduk, danau sehingga terjadilah eutrofikasi. Karena besarnya akibat yang ditimbulkan oleh erosi maka perlu dilakukan tindakan-tindakan untuk mengurangi erosi. Tindakan tersebut yaitu menerapkan teknik-teknik konservasi tanah dan air (Arsyad, 2010).

Salah satu tindakan konservasi tanah yang dapat dilakukan adalah menutup tanah dengan sisasisa tanaman (mulsa). Penutupan permukaan tanah dengan sisa-sisa tanaman dapat mencegah terjadinya pukulan butiran hujan secara langsung sehingga penghancuran agregat tanah yang merupakan tahap awal dari proses erosi dapat dihindarkan. Selain itu, penggunaan sisa-sisa tanaman juga dapat melindungi tanah dari daya perusak aliran permukaan dan memperbaiki kapasitas infiltrasi tanah serta penahanan air yang langsung mempengaruhi besarnya aliran permukaan (Parhadi, 2015).

Erosi juga dapat dicegah dengan menerapkan pengolahan tanah konservasi dimana tanah diolah 
seperlunya saja, bahkan pada kondisi lahan tertentu tanah tidak diolah sama sekali. Sistem olah tanah konservasi terdiri dari olah tanah minimum dan tanpa olah tanah. Pada sistem olah tanah minimum, tanah diolah hanya pada barisan tanaman saja dan sisa tanaman tidak dibuang tetapi dijadikan mulsa. Pada sistem tanpa olah tanah, tanah tidak diolah dan benih tanaman langsung ditanam pada lubang tugal. Khusus pada lahan yang berlereng, struktur tanah sebaiknya tidak dirusak oleh pengolahan tanah dan sisa tanaman dijadikan mulsa dan pengolahan tanah dilakukan memotong lereng atau menurut kontur, sehingga terbentuk jalur-jalur tumpukan tanah dan alur menurut kontur atau melintang lereng sehingga aliran permukaan dan erosi dapat dicegah seminimal mungkin (Banuwa, 2013).

Penelitian ini bertujuan untuk mengetahui pengaruh sistem olah tanah, penggunaan mulsa, dan interaksi antar keduanya terhadap kehilangan unsur hara $(\mathrm{N}, \mathrm{P}, \mathrm{K})$ dan C-organik akibat erosi pada lahan pertanaman kacang hijau.

\section{BAHAN DAN METODE}

Penelitian ini dilaksanakan pada bulan Maret sampai dengan bulan Juni tahun 2017 di Laboratorium Lapang Terpadu dan Laboratorium Ilmu Tanah, Fakultas Pertanian Universitas Lampung. Bahan-bahan yang digunakan pada penelitian ini adalah benih kacang hijau, sisa tanaman jagung dan sisa gulma, pupuk phonska, dan bahan lain yang digunakan untuk keperluan analisis tanah dan sedimen di laboratorium. Alat-alat yang digunakan adalah petak erosi berukuran
$4 \mathrm{~m} \mathrm{x} 4 \mathrm{~m}$ (Gambar 1), kantong plastik, pengukur erosi atau sedimen (saringan dan sendok), pengukur aliran permukaan (gelas ukur), pengukur curah hujan (ombrometer), cangkul, dan alat-alat yang digunakan pada saat analisis sampel tanah dan sedimen di laboratorium. Pengukuran erosi dilakukan dengan menggunakan metode pengukuran untuk satu kejadian hujan pada petak-petak kecil (multislot deviser). Penelitian ini menggunakan Rancangan Acak Kelompok Lengkap (RAKL) dengan dua faktorial. Faktor pertama adalah sistem olah tanah, yang terdiri dari $\mathrm{T}_{0}$ (pengolahan tanah minimum/minimum tillage) dan $\mathrm{T}_{1}$ (pengolahan tanah konvensional/full tillage). Faktor kedua adalah perlakuan mulsa yaitu $\mathrm{M}_{0}(\operatorname{tanpa}$ mulsa) dan $\mathrm{M}_{1}$ (pemberian mulsa). Setiap perlakuan dilakukan dalam empat kali pengulangan sehingga terdapat total 16 satuan percobaan, dimana setiap satuan percobaan ditempatkan pada petak erosi berkuran $4 \mathrm{~m} \times 4 \mathrm{~m}$.

Petak erosi yang digunakan pada penelitian ini terbuat dari beton dan terletak pada kemiringan lereng sebesar $12,5 \%$. Pada bagian bawah petak erosi terdapat bak penampung berukuran $100 \mathrm{~cm}$ x $50 \mathrm{~cm}$ x $50 \mathrm{~cm}$ yang berfungsi untuk menampung aliran permukaan dan tanah yang tererosi. Bak tersebut memiliki 5 buah lubang yang berfungsi untuk saluran pembuangan apabila volume air yang ada pada bak penampung terlalu banyak. Lubang yang berada ditengah bak penampung disalurkan menuju sebuah drum penampung yang berfungsi untuk mengukur besarnya jumlah aliran permukaan dan erosi pada saat kondisi meluap. Bak dan drum tersebut kemudian 


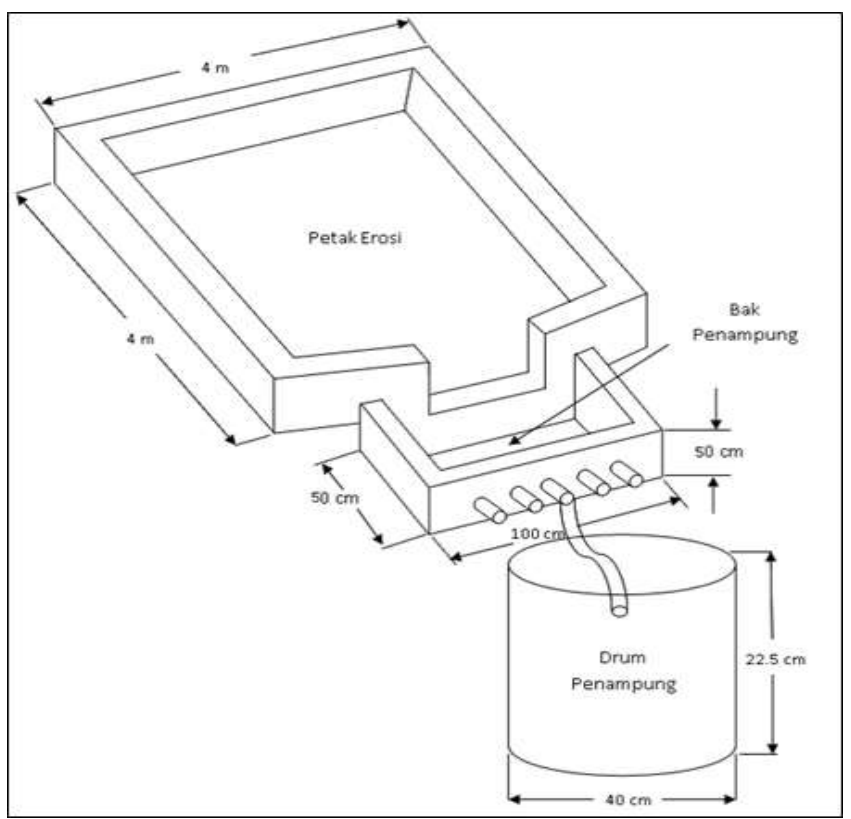

Gambar 1. Konstruksi Petak Erosi, Bak dan Drum Penampung di Lapangan.

ditutup dengan rapat agar tidak tercampur dengan air hujan sehingga data yang diperoleh akurat. Besarnya aliran permukaan dihitung dengan menggunakan rumus berikut:

$$
\mathrm{AP}=\mathrm{Vb}+(\mathrm{Vd} \times \mathrm{N})
$$

\section{Keteragan:}

$\mathrm{AP} \quad=$ Aliran Permukaan (liter)

$\mathrm{Vb}=$ Volume air yang berada di dalam bak (liter)

$\mathrm{Vd} \quad=$ Volume air yang ada di dalam drum (liter)

$\mathrm{N} \quad=$ Jumlah saluran pembuangan.

Pengolahan tanah dilakukan dengan menggunakan dua cara, yaitu pengolahan tanah konvensional (full tillage) dan pengolahan tanah minimum (minimum tillage). Pengolahan tanah dilakukan dengan membolak-balikkan tanah menggunakan cangkul hingga tanah menjadi gembur. Pengolahan tanah minimum (minimum tillage) yaitu pengolahan tanah yang dilakukan hanya pada lubang tanam dan permukaan tanah diberikan mulsa berupa sisa tanaman yang berasal dari musim tanam sebelumnya.

Penanaman kacang hijau dilakukan setelah pengolahan tanah dengan jarak tanam $30 \mathrm{~cm}$ x $70 \mathrm{~cm}$. Agar tanaman mendapatkan kebutuhan hara yang cukup, maka setiap perlakuan diberi tambahan pupuk phonska $200 \mathrm{~kg} \mathrm{ha}^{-1}$ dengan cara ditugal. Mulsa yang digunakan pada perlakuan adalah mulsa dari sisa tanaman jagung dan gulma. Dosis mulsa yang diberikan sebanyak 5 ton ha $^{-1}$ dan pemberian mulsa dilakukan 7 hari setelah tanam.

Pengumpulan data dilakukan dengan mengukur curah hujan, erosi, aliran permukan dan kandungan unsur hara $\mathrm{N}$-total (metode Kjeldahl), P-tersedia (metode Bray-1), K-dd (metode ekstaksi $\mathrm{NH}_{4} \mathrm{OAc}$ $1 \mathrm{~N} \mathrm{pH} \mathrm{7,0)} \mathrm{dan} \mathrm{C-organik} \mathrm{(metode} \mathrm{Walkey} \mathrm{and}$ Black).pada tanah asal dan sedimen. Nisbah pengayaan unsur hara $\mathrm{N}, \mathrm{P}, \mathrm{K}$ dan $\mathrm{C}$-organik dihitung dengan perbandingan konsentrasi suatu unsur hara di 
dalam tanah yang tererosi (sedimen) dengan konsentrasi unsur hara tersebut pada tanah asalnya dan kehilangan unsur hara N, P, K dan C-organik akibat erosi dihitung dengan mengalikan konsentrasi unsur hara dengan banyaknya tanah yang tererosi. Data dianalisis dengan menggunakan analisis ragam dan dilanjutkan dengan uji Beda Nyata Terkecil (BNT) pada taraf nyata $5 \%$

\section{HASIL DAN PEMBAHASAN}

\section{Konsentrasi Unsur Hara dalam Sedimen}

Hasil penelitan menunjukkan bahwa perlakuan pengolahan tanah, pemberian mulsa dan kombinasi keduanya tidak memberikan pengaruh nyata terhadap konsentrasi N-total, P-tersedia, K-dd dan C-organik dalam sedimen (Tabel 1). Kandungan unsur hara dalam sedimen yang tidak berbeda nyata tersebut dikarenakan aliran permukaan dan erosi yang tidak berbeda nyata (Tabel 5 dan 6).

Erosi yang tidak berbeda nyata antar perlakuan disebabkan karena curah hujan yang rendah selama penelitian. Total curah hujan yang terukur selama penelitian (hujan hanya turun pada bulan Juni) adalah16,26 mm. Penggolongan iklim menurut Mohr (1993, dalam Kartasapoetra, 2006) didasarkan pada bulan basah dan bulan kering. Dikatakan bulan basah jika curah hujan melebihi 100 mm sedangkan untuk bulan kering curah hujan kurang dari $60 \mathrm{~mm}$. Berdasarkan penggolongan iklim terebut, curah hujan selama penelitian ini digolongkan pada bulan kering dikarenakan curah hujan yang terukur kurang dari 60 mm. Curah hujan yang rendah pada penelitian ini

Tabel 1. Pengaruh sistem olah tanah dan pemberian mulsa terhadap kandungan unsur hara di dalam sedimen.

\begin{tabular}{|c|c|c|c|c|c|c|}
\hline \multirow{3}{*}{ Perlakuan } & \multicolumn{6}{|c|}{ Unsur Hara } \\
\hline & \multicolumn{2}{|c|}{ N-total $(\%)$} & \multirow{2}{*}{$\begin{array}{c}\text { P-tersedia } \\
\text { (ppm) }\end{array}$} & \multirow{2}{*}{$\begin{array}{c}\text { K-dd } \\
(\text { me 100g-1) }\end{array}$} & \multicolumn{2}{|c|}{ C-organik (\%) } \\
\hline & Asli & $\begin{array}{c}\text { Trans } \\
\text { Arc-sin } \mathrm{x} \\
\end{array}$ & & & Asli & $\begin{array}{c}\text { Trans } \\
\text { Arc-sin } \mathrm{x}\end{array}$ \\
\hline $\mathrm{T}_{0} \mathrm{M}_{0}$ & 0,17 & $2,25 \mathrm{a}$ & $41,35 \mathrm{a}$ & $0,64 \mathrm{a}$ & 1,81 & 7,63a \\
\hline $\mathrm{T}_{0} \mathrm{M}_{1}$ & 0,23 & $2,72 \mathrm{a}$ & $39,24 a$ & $0,68 \mathrm{a}$ & 2,42 & $8,88 \mathrm{a}$ \\
\hline $\mathrm{T}_{1} \mathrm{M}_{0}$ & 0,19 & $2,47 \mathrm{a}$ & $37,68 \mathrm{a}$ & $0,64 \mathrm{a}$ & 1,96 & $8,03 \mathrm{a}$ \\
\hline $\mathrm{T}_{1} \mathrm{M}_{1}$ & 0,16 & $2,25 \mathrm{a}$ & $41,33 \mathrm{a}$ & $0,53 \mathrm{a}$ & 1,71 & $7,49 \mathrm{a}$ \\
\hline BNT 5\% & & 0,72 & 9,21 & 0,14 & & 1,67 \\
\hline
\end{tabular}

Tabel 2. Pengaruh sistem olah tanah dan pemberian mulsa terhadap nisbah pengayaan.

\begin{tabular}{|c|c|c|c|c|c|c|}
\hline \multirow{3}{*}{ Perlakuan } & \multicolumn{6}{|c|}{ Unsur Hara } \\
\hline & \multicolumn{2}{|c|}{ N-total } & \multirow[b]{2}{*}{ P-tersedia } & \multirow[b]{2}{*}{ K-dd } & \multicolumn{2}{|c|}{ C-organik } \\
\hline & Asli & $\begin{array}{c}\text { Trans } \\
\text { Arc-sin } \mathrm{x}\end{array}$ & & & Asli & $\begin{array}{c}\text { Trans } \\
\text { Arc-sin } x\end{array}$ \\
\hline $\mathrm{T}_{0} \mathrm{M}_{0}$ & 0,97 & $5,47 \mathrm{a}$ & $0,81 \mathrm{a}$ & $0,94 \mathrm{a}$ & 0,75 & $4,92 \mathrm{a}$ \\
\hline $\mathrm{T}_{0} \mathrm{M}_{1}$ & 1,34 & $6,60 \mathrm{a}$ & $0,77 \mathrm{a}$ & $1,00 \mathrm{a}$ & 1,01 & $5,73 a$ \\
\hline $\mathrm{T}_{1} \mathrm{M}_{0}$ & 1,1 & $6,01 \mathrm{a}$ & $0,74 a$ & $0,94 \mathrm{a}$ & 0,82 & $5,18 \mathrm{a}$ \\
\hline $\mathrm{T}_{1} \mathrm{M}_{1}$ & 0,91 & $5,46 a$ & $0,81 \mathrm{a}$ & $0,77 \mathrm{a}$ & 0,71 & $4,83 \mathrm{a}$ \\
\hline BNT 5\% & & 1,75 & 0,18 & 0,21 & & 1,07 \\
\hline
\end{tabular}


mengakibatkan proses penghancuran partikel-partikel tanah akibat energi kinetik air hujan menjadi rendah. Curah hujan yang rendah dapat menyebabkan air hujan yang jatuh ke tanah sebagian besar mengalami infiltrasi yang berdampak terhadap rendahnya laju aliran permukaan pada semua perlakuan sehingga aliran permukaan dan erosi tidak berbeda nyata antar perlakuan.

Erosi yang terjadi adalah erosi percik, dimana energi kinetik butir-butir hujan memecah struktursruktur tanah menjadi butir-butir primer tanah. Erosi percik merupakan tahap awal dari proses erosi. Setelah terjadi penggenangan dengan ketebalan tiga kali diameter butir hujan, maka erosi percik berhenti dan dilanjutkan dengan erosi gerusan yang disebabkan oleh gerusan aliran permukaan. Tahap pengangkutan oleh aliran permukaan terjadi setelah terjadi penggenangan karena infiltrasi terhambat (Arsyad, 2010).

\section{Nisbah Pengayaan}

Hasil penelitian menunjukkan bahwa perlakuan pengolahan tanah, pemberian mulsa dan kombinasi keduanya tidak memberikan pengaruh nyata terhadap nisbah pengayaan $\mathrm{N}$-total,

P-tersedia, K-dd dan C-organik (Tabel 2). Menurut Arsyad (2010) nisbah pengayaan didefinisikan sebagai perbandingan konsentrasi suatu unsur hara di dalam tanah yang terangkut erosi atau sedimen dengan konsentrasi unsur tersebut di dalam tanah asalnya. Berdasarkan hal tersebut maka sedimen akan mengandung unsur hara yang lebih tinggi dibandingkan tanah asalnya. Pengayaan ini berasal dari sifat selektif erosi terhadap partikel-partikel halus tanah. Erosi akan bersifat lebih selektif terhadap partikel yang berukuran koloid seperti liat apabila laju erosi kecil tetapi apabila laju erosi tinggi komposisi tanah tererosi dan tanah asalnya sama.

Tabel 3. Pengaruh sistem olah tanah dan pemberian mulsa terhadap kehilangan unsur hara N-total dan P-tersedia akibat erosi.

\begin{tabular}{|c|c|c|c|c|}
\hline \multirow{3}{*}{ Perlakuan } & \multicolumn{4}{|c|}{ Unsur Hara } \\
\hline & \multicolumn{2}{|c|}{ N-total $\left(\mathrm{kg} \mathrm{ha}^{-1}\right)$} & \multicolumn{2}{|c|}{ P-tersedia $\left(\mathrm{kg} \mathrm{ha}^{-1}\right)$} \\
\hline & Asli & Trans $(\sqrt{ }(x+0,5))$ & Asli & Trans $(\sqrt{ }(\mathrm{x}+0,5))$ \\
\hline $\mathrm{T}_{0} \mathrm{M}_{0}$ & 0,0418 & $0,7356 \mathrm{a}$ & 0,0096 & $0,7139 a$ \\
\hline $\mathrm{T}_{0} \mathrm{M}_{1}$ & 0,0445 & $0,7377 \mathrm{a}$ & 0,0081 & $0,7128 \mathrm{a}$ \\
\hline $\mathrm{T}_{1} \mathrm{M}_{0}$ & 0,0638 & $0,7504 \mathrm{a}$ & 0,0124 & $0,7158 \mathrm{a}$ \\
\hline $\mathrm{T}_{1} \mathrm{M}_{1}$ & 0,0823 & $0,7623 \mathrm{a}$ & 0,0211 & $0,7218 \mathrm{a}$ \\
\hline BNT 5\% & & 0,0496 & & 0,011 \\
\hline $\mathrm{T}_{1}$ & 0,0731 & $0,7564 a$ & 0,0168 & $0,7188 \mathrm{a}$ \\
\hline $\mathrm{T}_{0}$ & 0,0431 & $0,7567 \mathrm{a}$ & 0,0089 & $0,7133 \mathrm{a}$ \\
\hline BNT 5\% & & 0,0351 & & 0,0078 \\
\hline $\mathrm{M}_{0}$ & 0,0528 & $0,7430 \mathrm{a}$ & 0,011 & $0,7148 \mathrm{a}$ \\
\hline $\mathrm{M}_{1}$ & 0,0634 & $0,7500 \mathrm{a}$ & 0,0146 & $0,7173 \mathrm{a}$ \\
\hline BNT 5\% & & 0,0351 & & 0,0078 \\
\hline
\end{tabular}


Menurut Burhannudin (2015) nilai nisbah pengayaan yang didapat kurang dari satu $(<1)$ maka konsentrasi unsur hara yang terdapat dalam sedimen lebih rendah dari konsentrasi unsur hara pada tanah asalnya. Nilai nisbah pengayaan sama dengan satu $(=1)$ maka konsentrasi unsur hara pada sedimen sama dengan konsentrasi unsur hara pada tanah asalnya. Nilai nisbah pengayaan yang didapat lebih dari satu $(>1)$ maka konsentrasi unsur hara yang terdapat dalam sedimen lebih tinggi dari konsentrasi unsur hara pada tanah asalnya.

Nisbah pengayaan N-total pada perlakuan $\mathrm{T}_{0} \mathrm{M}_{0}$ dan $\mathrm{T}_{1} \mathrm{M}_{1}$; nisbah pengayaan P-tersedia perlakuan $\mathrm{T}_{0} \mathrm{M}_{0}, \mathrm{~T}_{0} \mathrm{M}_{1}, \mathrm{~T}_{1} \mathrm{M}_{0}$ dan $\mathrm{T}_{0} \mathrm{M}_{1}$; dan nisbah pengayaan K-dd dan C-organik pada perlakuan $\mathrm{T}_{0} \mathrm{M}_{0}$, $\mathrm{T}_{1} \mathrm{M}_{0}$ dan $\mathrm{T}_{1} \mathrm{M}_{1}$ memiliki nilai kurang dari satu $(<1)$, artinya konsentrasi unsur hara dalam sedimen lebih rendah dibandingkan tanah asalnya. Nisbah pengayaan K-dd dan C-organik pada perlakuan $\mathrm{T}_{0} \mathrm{M}_{1}$ memiliki nilai sama dengan satu $(=1)$ sehingga konsentrasi unsur hara dalam sedimen sama dengan tanah asalnya. Selanjutnya nisbah pengayaan N-total pada perlakuan $\mathrm{T}_{0} \mathrm{M}_{1}$ dan $\mathrm{T}_{1} \mathrm{M}_{0}$ memiliki nilai lebih dari satu $(>1)$, dengan demikian konsentrasi unsur hara dalam sedimen lebih tinggi dibandingkan tanah asalnya.

\section{Kehilangan Unsur Hara Akibat Erosi}

Erosi akan memberikan dampak di tempat terjadinya erosi dan di luar tempat kejadian erosi. Dampak erosi di luar tempat kejadian erosi akan menyebabkan sedimentasi, sedangkan pada tempat terjadinya erosi mengakibatkan kehilangan lapisan tanah dan unsur hara. Hasil analisis ragam

Tabel 4. Pengaruh sistem olah tanah dan pemberian mulsa terhadap kehilangan unsur hara K-dd dan C-organik akibat erosi.

\begin{tabular}{ccccc}
\hline \multirow{2}{*}{ Perlakuan } & \multicolumn{4}{c}{ Unsur Hara } \\
\cline { 2 - 5 } & Asli & Trans $(\sqrt{ }(\mathrm{x}+0,5))$ & Asli & C-organik $\left(\mathrm{kg} \mathrm{han}^{-1}\right)$ \\
\cline { 2 - 5 } & 0,006 & $0,7113 \mathrm{a}$ & 0,383 & $0,9323 \mathrm{a}$ \\
\hline $\mathrm{T}_{0} \mathrm{M}_{0}$ & 0,0058 & $0,7112 \mathrm{a}$ & 0,4928 & $0,9861 \mathrm{a}$ \\
$\mathrm{T}_{0} \mathrm{M}_{1}$ & 0,0089 & $0,7133 \mathrm{a}$ & 0,6649 & $1,0620 \mathrm{a}$ \\
$\mathrm{T}_{1} \mathrm{M}_{0}$ & 0,0106 & $0,7145 \mathrm{a}$ & 0,8917 & $1,1557 \mathrm{a}$ \\
$\mathrm{T}_{1} \mathrm{M}_{1}$ & 0,0097 & 0,0066 & 0,3289 \\
\hline BNT 5\% & $0,7139 \mathrm{a}$ & 0,7783 & $1,1089 \mathrm{a}$ \\
\hline $\mathrm{T}_{1}$ & 0,0059 & $0,7112 \mathrm{a}$ & 0,4379 & $0,9592 \mathrm{a}$ \\
\hline $\mathrm{T}_{0}$ & 0,0046 & 0,2325 \\
\hline BNT 5\% & $0,7123 \mathrm{a}$ & $0,9971 \mathrm{a}$ \\
\hline $\mathrm{M}_{0}$ & 0,0082 & $0,7128 \mathrm{a}$ & 0,524 & 0,2325 \\
\hline $\mathrm{M}_{1}$ & \multicolumn{5}{c}{0,0046} \\
\hline BNT 5\%
\end{tabular}

Keterangan : $-\mathrm{T}_{0} \mathrm{M}_{0}=$ Pengolahan tanah minimum tanpa pemberian mulsa.

$-\mathrm{T}_{0} \mathrm{M}_{1}=$ Pengolahan tanah minimum + pemberian mulsa.

$-\mathrm{T}_{1} \mathrm{M}_{0}=$ Pengolahan tanah konvensional tanpa pemberian mulsa.

$-\mathrm{T}_{1} \mathrm{M}_{1}=$ Pengolahan tanah konvensional + pemberian mulsa.

- Angka-angka yang diikuti oleh huruf yang sama tidak berbeda nyata berdasarkan uji BNT taraf 5\%. 
menunjukkan bahwa perlakuan pengolahan tanah, pemberian mulsa dan kombinasi keduanya tidak memberikan pengaruh nyata terhadap kehilangan Ntotal, P-tersedia, K-dd dan C-organik. N-total, Ptersedia, K-dd dan C-organik yang terangkut oleh erosi tidak berbeda nyata antar perlakuan (Tabel 3 dan 4). Hal ini terjadi karena erosi yang dihasilkan tidak berbeda nyata. Erosi yang tidak berbeda nyata tersebut menyebabkan unsur hara yang terangkut pada sedimen juga tidak berbeda nyata.

Tabel 3 dan 4 juga menunjukkan bahwa Ntotal, P-tersedia, K-dd dan C-oganik yang hilang akibat erosi pada perlakuan olah tanah minimum $\left(\mathrm{T}_{0}\right)$ tidak berbeda nyata dibandingkan pada perlakuan olah tanah konvensional $\left(\mathrm{T}_{1}\right)$. Besarnya kehilangan $\mathrm{N}$-total, $\mathrm{P}$ tersedia, K-dd dan C-organik akibat erosi secara berturut-turut pada olah tanah minimum $\left(\mathrm{T}_{0}\right)$ sebesar 0,0431 kg ha-1; 0,0089 $\mathrm{kg} \mathrm{ha}^{-1} ; 0,0059 \mathrm{~kg} \mathrm{ha}^{-1}$ dan $0,4379 \mathrm{~kg} \mathrm{ha}^{-1}$ sedangkan pada olah tanah konvensional $\left(\mathrm{T}_{1}\right)$ sebesar $0,0731 \mathrm{~kg} \mathrm{ha}^{-1} ; 0,0168 \mathrm{~kg}$ $\mathrm{ha}^{-1} ; 0,0097 \mathrm{~kg} \mathrm{ha}^{-1}$ dan $0,7783 \mathrm{~kg} \mathrm{ha}^{-1}$. Dengan demikian, total kehilangan unsur hara pada perlakuan olah tanah minimum $\left(\mathrm{T}_{0}\right)$ sebesar $0,4958 \mathrm{~kg} \mathrm{ha}^{-1}$ sedangkan pada olah tanah konvensional $\left(\mathrm{T}_{1}\right)$ sebesar

Tabel 5. Analisis ragam pengaruh sistem olah tanah dan pemberian mulsa terhadap aliran permukaan (mm) hasil transformasi $\sqrt{ }(\mathrm{x}+0,5)$

\begin{tabular}{|c|c|c|c|c|c|c|}
\hline \multirow{2}{*}{$\begin{array}{c}\text { Sumber } \\
\text { Keragaman }\end{array}$} & \multirow{2}{*}{$\begin{array}{c}\text { Derajat } \\
\text { Kebebasan }\end{array}$} & \multirow{2}{*}{$\begin{array}{c}\text { Jumlah } \\
\text { Kuadrat }\end{array}$} & \multirow{2}{*}{$\begin{array}{c}\text { Kuadrat } \\
\text { Tengah }\end{array}$} & \multirow{2}{*}{ F-hitung } & \multicolumn{2}{|c|}{ F-tabel } \\
\hline & & & & & $5 \%$ & $1 \%$ \\
\hline Kelompok & 3 & 0,1 & 0,03 & $0,33^{\text {tn }}$ & 3,86 & 6,99 \\
\hline Perlakuan & 3 & 0,12 & 0,04 & $0,40^{\text {tn }}$ & 3,86 & 6,99 \\
\hline Olah Tanah & 1 & 0,04 & 0,04 & $0,37^{\mathrm{tn}}$ & 5,12 & 10,56 \\
\hline Mulsa & 1 & 0,07 & 0,07 & $0,71^{\text {tn }}$ & 5,32 & 10,56 \\
\hline OT x M & 1 & 0,01 & 0,01 & $0,11^{\mathrm{tn}}$ & 5,12 & 10,56 \\
\hline Galat & 9 & 0,91 & 0,1 & & & \\
\hline Nonaditifitas & 1 & 0,13 & 0,13 & $1,31^{\mathrm{tn}}$ & 5,32 & 11,26 \\
\hline Sisa & 8 & 0,79 & 0,1 & & & \\
\hline Total & 15 & 1,13 & 0,08 & & & $36 \%$ \\
\hline
\end{tabular}

Tabel 6. Analisis ragam pengaruh sistem olah tanah dan pemberian mulsa terhadap erosi $\left(\mathrm{kg} \mathrm{ha}^{-1}\right)$ hasil transformasi $\sqrt{ }(x+0,5)$

\begin{tabular}{ccccccc}
\hline Sumber & Derajat & Jumlah & Kuadrat & \multirow{2}{*}{ F-hitung } & \multicolumn{2}{c}{ F-tabel } \\
\cline { 6 - 7 } Keragaman & Kebebasan & Kuadrat & Tengah & & $5 \%$ & $1 \%$ \\
\hline Kelompok & 3 & 0,55 & 0,18 & $1,09^{\text {tn }}$ & 3,86 & 6,99 \\
Perlakuan & 3 & 0,51 & 0,17 & $1,01^{\text {tn }}$ & 3,86 & 6,99 \\
Olah Tanah & 1 & 0,4 & 0,4 & $2,36^{\text {tn }}$ & 5,12 & 10,56 \\
Mulsa & 1 & 0,04 & 0,04 & $0,27^{\text {tn }}$ & 5,32 & 10,56 \\
OT x M & 1 & 0,07 & 0,07 & $0,40^{\text {tn }}$ & 5,12 & 10,56 \\
Galat & 9 & 1,51 & 0,17 & & & \\
Nonaditifitas & 1 & 0,24 & 0,24 & $1,51^{\text {tn }}$ & 5,32 & 11,26 \\
Sisa & 8 & 1,27 & 0,16 & & & KK= $=17,12 \%$ \\
\hline Total & 15 & 2,56 & 0,17 & & &
\end{tabular}


$0,8779 \mathrm{~kg} \mathrm{ha}^{-1}$. Hal tersebut didukung oleh hasil penelitian Burhannudin (2015) yang menyatakan bahwa pengolahan tanah konvensional (full tillage) dan pengolahan tanah minimum (minimum tillage) tidak berpengaruh nyata terhadap kehilangan N-total, Ptersedia, K-dd dan C-organik akibat erosi.

\section{KESIMPULAN}

Dari hasil penelitian ini disimpulkan bahwa perlakuan sistem olah tanah konservasi, perlakuan mulsa dan interaksi antara keduanya tidak berpengaruh nyata terhadap kandungan N-total, P-tersedia, K-dd dan C-organik dalam sedimen.

\section{DAFTAR PUSTAKA}

Arsyad, S. 2010. Konservasi Tanah dan Air. IPB Press. Bogor. $472 \mathrm{hlm}$.

Banuwa, I. S. 2013. Erosi. Kencana Prenada Media Group. Jakarta. $204 \mathrm{hlm}$.
Burhannudin. 2015. Pengaruh sistem olah tanah dan herbisida terhadap kehilangan unsur hara dan bahan organik akibat erosi di Laboratorium Lapangan Terpadu Fakultas Pertanian Universitas Lampung. Jurnal Teknik Pertanian Lampung, 3(3): 275-282.

Kartasapoetra,A.G. 2006. Klimatologi: Pengaruh Iklim Terhadap Tanah dan Tanaman. Bumi Aksara. Jakarta. 101 hlm.

Parhadi. 2015. Pengaruh mulsa jerami terhadap laju erosi pada tanah mediteran. Jurnal Wahana Teknik Sipil, 20 (1): 33-47.

Wardani, M.C.W. 1990. Pengaruh pemberian mulsa dan pengolahan tanah terhadap kehilangan bahan organik, N, P, K, Ca, dan Mg melalui erosi selama satu tahun musim kacang tanah (Arachis hypogaea L.) varietas Pelandung pada Dystropept Oksik Darmaga. Skripsi. Fakultas Pertanian IPB. Bogor. $66 \mathrm{hlm}$. 